\title{
Sustainability performance of corporations: comparison of assessment methods
}

\author{
R. J. Baumgartner \\ University of Leoben, Austria
}

\begin{abstract}
The concept of sustainable development is of increasing importance for societies. Corporations play an essential role as relevant societal actors for the realization and implementation of sustainable development. Therefore it is necessary to assess the performance of corporations in the light of sustainable development. In this paper, basic methods and instruments for the assessment of corporate sustainability performance are compared. Sustainability assessments can be divided in two groups: the first group consists of methods based on monetary units, the second group consists of methods based on non-monetary units. The methods of sustainable value, composite sustainable development index and integrated sustainability assessment are discussed in detail and evaluated regarding the criteria applicability, contribution to basic goals of sustainable development, completeness and advantages / disadvantages. The methods are additionally used to assess the sustainability performance of BP and Royal Dutch/Shell Group.

Keywords: sustainability assessment, sustainable development, corporate sustainability performance, sustainable value, integrated sustainability assessment, composite sustainable development index, Royal Dutch/Shell, BP Group
\end{abstract}

\section{Introduction}

Assessing the sustainability performance of corporations is an important aspect within the transition of societies towards the principles of sustainable development. In this paper three methods are presented. Sustainable value is based on monetary units and assesses the value a company creates by using resources compared to a benchmark. Composite sustainable development index 
and integrated sustainability assessment are based on non-monetary units. These methods use different indicators for each dimension of Sustainable development and combine them either with value benefit analysis or Fuzzy Logic. Depending on the goals used for the benchmark relative and absolute contributions to sustainable development can be assessed.

The objective of sustainable development [1] is sustainability, which can be characterized by four principles. First, contribution to systematic increase in concentrations of substances from the earth's crust has to be eliminated. Second, contribution to systematic increases in concentrations of substances produced by society has to be eliminated. Third, contribution to the systematic physical degradation of nature through over-harvesting, introductions and other forms of modification has to be eliminated. Fourth, contribute as much as possible to the meeting of human needs in our society and worldwide, over and above all measures taken in meeting the first three objectives [2].

\section{Assessment of corporate sustainability}

In this paper several methods for the assessment of corporate sustainability are compared. The chosen methods are either widely used in practise or highlighting important aspects of sustainability assessments of corporations.

\subsection{Sustainable value added}

The method of sustainable value added has been developed by Figge and Hahn [3]. It is based on opportunity costs and shows how much more value is created because a company is more efficient than a benchmark and because the resources are allocated to the company and not to benchmark companies. With this method the relative corporate contribution to sustainability can be measured in absolute monetary terms. It does not show - if the use of the resource by this entity is sustainable in absolute terms - but it indicates how much more sustainable (in monetary terms) the use of the resource is in comparison to other entities [3, p. 177].

The sustainable value is calculated in five steps [4, pp. 18].

How much of a resource does a company use?

The first step determines the amount of resources the company uses during the year including economic, environmental and social resource.

How much return does the company create with these resources?

In this step the return the company creates with these resources is measured. It can be measured with gross value added [4, p. 19], which represents a company's contribution to gross domestic product (GDP), or with net value added [5]. By dividing the gross value added with the amount of a resource used by the company the resource efficiency can be calculated.

How much return would the benchmark create with these resources?

This step determines how much return would be created, if the resources were used not by the company but by the benchmark. Each resource can be used only once. Therefore, we cannot benefit from both, the return the company creates 
and the return the benchmark would create. As the company uses the resources, the return the benchmark would create is foregone. The foregone return is equivalent to opportunity cost.

Which resources are used in a value-creating way by the company and which are not?

The return the company creates with each resource is compared with the return created by the benchmark. The return the company creates corresponds to its gross value added, the return of the benchmark are the opportunity costs. The value contribution is calculated by subtracting the opportunity costs of each resource from the gross value added. It shows how much more or less value a company creates with a resource compared to the benchmark.

How much sustainable value does the company create?

The sustainable value is calculated by dividing the sum of the value contributions by the number of resources considered. Simply summing up the value contributions would result in double counting as the bundle of used resources creates the value.

\subsection{Composite sustainable development index}

This method was presented by Krajnc and Glavic 2005 [6, 7]. It is based on nonmonetary units. The model reduces the number of indicators by aggregating them into a composite sustainable development index ( $\left.\mathrm{I}_{\mathrm{CSD}} ; 0 \leq \mathrm{I}_{\mathrm{CSD}} \leq 1\right)$. The index consists of an economic sub-index $\left(\mathrm{I}_{\mathrm{S}, 1}\right)$, an environmental sub-index $\left(\mathrm{I}_{\mathrm{S}, 2}\right)$ and a social sub-index $\left(\mathrm{I}_{\mathrm{S}, 3}\right)$. The sub-indices are built of normalized indicators.

The procedure of calculating the Index is divided into several parts $[7,8]$.

Selection, grouping and judging the indicators

First, proper performance indicators are selected covering different aspects of sustainability. Then the indicators are grouped to the three dimensions of Sustainable development. Economic group of indicators concerns the impacts of the company on the economic well being of its stakeholders and on economic systems. Environmental group of indicators cover impacts of the company on the ecosphere. Societal group of indicators reflects the impact of the company on its stakeholders and the society. Additionally it is regarded whether an increased value of an indicator has a positive or negative impact on sustainability performance. For example, increased value of air emissions per unit of production has a negative impact; this indicator is of type "less is better".

\section{Weighting}

Pair-wise comparison technique is used to derive relative weights of each indicator. This method is based on the Analytic Hierarchy Process (AHP) [8].

\section{Normalizing}

Indicators used for the composite sustainable development index are expressed in different units. Therefore they have to be normalized. Krajnc and Glavic suggest two methods for normalization [6]: First possibility is to divide the value in time of an indicator with its target value determined by realistic assessment of unexploited potentials for the company. The second possibility is to normalize the indicator dividing the difference between actual and minimum level with the 
difference between maximum and minimum level of this indicator (for indicators of type "more is better") respectively to subtract the result of this division from 1 for indicators of the type "less is better" (see Figure 1).

Calculating sub-indices and combining to composite sustainable development index

The sub-indices are calculated by multiplying each indicator value with its weight and summing up all multiplications (value benefit analysis). Accordingly, the composite index is calculated by multiplying each sub-index with its weight and summing up the three results for the sub-indices.

\subsection{Integrated sustainability assessment}

Baumgartner introduced integrated sustainability assessment for the assessment of products, services and technologies [9, 10]. This method can also be used for assessing the sustainability performance of a company. The central element is the combined assessment - based on fuzzy logic [11] - of the environmental, economic and social dimension of Sustainable development. Fuzzy logic enables specific weighting of social, economic and ecological aspects and translates blurred input signals into stable global results. Fuzzy logic can combine indicators that are measured in different units. The structure of a fuzzy-based scoring model consists of the steps defining logical composition rules, fuzzification, inference and defuzzification [10, 12, p. 69].

Defining logical composition rules

The logical composition rules are defined as If-then-conclusions. The rules consist of a condition and a consequence part. An example of a rule could be as follows: "If the improvement of the environmental performance is small and the creation of value is strongly worsened then the total evaluation is worse."

In the condition section several premises (here "environmental performance" and "creation of value") can be combined with the help of logical relations. Premises and consequences are linguistic variables, the terms (values) of the variables are words or sentences. Eeach term is defined by an appropriate membership function $\mu(0 \leq \mu \leq 1)$, which can have triangular, trapezoidal or bell-type shapes [13, pp. 44]). In our case, triangular membership functions are used.

\section{Fuzzification}

The membership functions of the terms of the linguistic variable have to be determined, which is called fuzzification.

\section{Inference}

In this step conclusions from the premises to the consequences have to be made. For instance a rule is defined as followed: "If the improvement of the environmental performance is small and the creation of value is strongly worsened then the total evaluation is worse". The membership function for environmental performance (small) is $\mu=0.3$ and for value creation (strongly worsened) is $\mu=0.7$, the inference defines the membership function for total evaluation (unacceptable). The results depend on the logical operator used in the condition part. Basis operators are "and", which represents a minimum operator, 
and "or", which is a maximum operator. In our example, "and" is used, therefore the conclusion is defined with $\mu=0.3$ [14, p. 123].

Defuzzification

Here a sharp value of the membership functions of the conclusions is calculated. Therefore different methods exist - a simple, but sufficient represents the socalled Singleton procedure [14, p. 124].

\section{Application of sustainable value, composite sustainability index and integrated sustainability assessment: the example of BP and Royal Dutch/Shell}

The application of the methods sustainable value, composite sustainable development index and integrated sustainability assessment is demonstrated with the example of BP and Royal Dutch/Shell for the year 2003.

Table 1: $\quad$ Sustainable value of Royal Dutch/Shell and BP [4, p. 139, p. 98].

\begin{tabular}{|c|c|c|}
\hline 2003 & Shell Group & BP Group \\
\hline \multicolumn{3}{|c|}{ Performance } \\
\hline Gross value added [€] & $37,102,687,000$ & $30,651,662,600$ \\
\hline Sales $[€]$ & $238,076,976,800$ & $205,918,363,400$ \\
\hline $\mathrm{CO}_{2}$-emissions $[\mathrm{t}]$ & $106,000,000$ & $88,890,000$ \\
\hline $\mathrm{NO}_{\mathrm{x}}$-emissions $[\mathrm{t}]$ & 220,000 & 220,318 \\
\hline $\mathrm{SO}_{\mathrm{x}}$-emissions $[\mathrm{t}]$ & 292,000 & 150,895 \\
\hline Waste $[\mathrm{t}]$ & $1,064,000$ & 526,749 \\
\hline Water used $\left[\mathrm{m}^{3}\right]$ & $1,690,000,000$ & $516,922,761$ \\
\hline VOC-emissions [t] & 294,000 & 268,785 \\
\hline $\mathrm{CH}_{4}$-emissions [t] & 234,000 & 235,400 \\
\hline \multicolumn{3}{|c|}{ Opportunity Costs of resource use by the company } \\
\hline $\mathrm{CO}_{2}$-emissions $[€]$ & $286,352,338,596$ & $240,130,748,847$ \\
\hline $\mathrm{NO}_{\mathrm{x}}$-emissions $[€]$ & $220,945,957,291$ & $221,265,324,629$ \\
\hline $\mathrm{SO}_{\mathrm{x}}$-emissions $[€]$ & $519,556,661,315$ & $268,488,021,949$ \\
\hline Waste $[€]$ & $6,671,127,687$ & $3,303,640,825$ \\
\hline Water used $[€]$ & $70,089,609,574$ & $21,438,410,946$ \\
\hline VOC-emissions $[€]$ & $285,378,845,537$ & $260,903,241,488$ \\
\hline $\mathrm{CH}_{4}$-emissions $[€]$ & $137,143,400,225$ & $137,963,916,295$ \\
\hline \multicolumn{3}{|c|}{ Value Contributions } \\
\hline $\mathrm{CO}_{2}$-emissions [€] & $-249,249,651,596$ & $-209,479,086,247$ \\
\hline $\mathrm{NO}_{\mathrm{x}}$-emissions $[€]$ & $-183,843,270,291$ & $-190,613,662,029$ \\
\hline $\mathrm{SO}_{\mathrm{x}}$-emissions $[€]$ & $-482,453,974,315$ & $-237,836,359,349$ \\
\hline Waste $[€]$ & $30,431,559,313$ & $27,349,021,775$ \\
\hline Water used $[€]$ & $-32,986,922,574$ & $9,213,251,654$ \\
\hline VOC-emissions $[€]$ & $-248,276,158,537$ & $-230,251,578,888$ \\
\hline $\mathrm{CH}_{4}$-emissions $[€]$ & $-100,40,713,225$ & $-107,312,253,695$ \\
\hline Sustainable Value & $-180,917,018,746$ & $-134,132,952,397$ \\
\hline Rank & 49 & 47 \\
\hline Return to Cost Ratio & $1: 5.9$ & $1: 5.4$ \\
\hline
\end{tabular}




\subsection{Sustainable value}

This example is taken from the advance project, a research project funded by the EU and participating organizations [4, 15]. ADVANCE applies the Sustainable value approach to assess the use of 7 environmental resources by 65 European companies from 16 countries and 18 different sectors. The considered environmental resources are carbon dioxide $\left(\mathrm{CO}_{2}\right)$ emissions, nitrogen oxide $\left(\mathrm{NO}_{\mathrm{x}}\right)$ emissions, sulphur oxide $\left(\mathrm{SO}_{\mathrm{x}}\right)$ emissions, emissions of volatile organic compounds (VOC), methane (CH4) emissions, waste generation and water use. In this case, the social dimension is not considered. The benchmark consists of the eco-efficiency of the EU15 countries (member states before enlargement in 2003). The size of the companies is taken with the Return to Cost Ratio into account. It relates the gross value added created by the company to the opportunity costs it causes and is therefore a typical benefit-cost-ratio. If the return to cost ratio is smaller than 1 the company uses its set of resources less efficiently than the benchmark. In this case the company destroys sustainable value $[4$, pp. 23].

The results show for Royal Dutch/Shell group a sustainable value of $-180,917,018,746$ Euro. BP Group reached a sustainable value of $-134,132,952,397$ Euro. Both companies are producing less value than the Benchmark and are destroying sustainable value. Their business is relative unsustainable compared to the eco-efficiency of the EU15. BP shows better results, mainly due to lower emissions of $\mathrm{SO}_{\mathrm{x}}$ and waste (see Table 1).

\subsection{Composite sustainable development index}

This example was published by Krajnc and Glavic 2005 [7]. It shows the application of the Composite Sustainable development Index on Royal Dutch/Shell and BP group. Table 2 and 3 present the results. In this example the social and the economic dimension are assessed, too.

Also in this case, BP is performing better than Shell. BP performs in the economic and environmental dimension better than Shell, which shows a better performance in the social dimension.

\subsection{Integrated sustainability assessment}

For this example, data from Krajnc and Glavic [7] and the advance project [4] are used. The assessment is relative, this means that Shell group is assessed relative to BP group. The criteria $\mathrm{CO}_{2}, \mathrm{NO}_{x}, \mathrm{CH}_{4}, \mathrm{SO}_{2}$ and hazardous wastes are used for the environmental dimension, cash flow is used for the economic dimension and fraction of societal and community investment in gross profit and recordable injury frequency for employees and contractors (all values see table 2) are used for the social dimension. Each criterion is defined as linguistic variable with the linguistic terms "better", "identical" and "worse" on a scale from 0 to 100 points; triangulare membership functions are used. Each criterion is assessed relative, this means that the ratio from the values for Shell against BP is calculated. This ratio is normalized and used as input for the linguistic 
variables. 100 points corresponds to an increase of $50 \%$ of positive indicators (like cash flow) respectively to a decrease of $50 \%$ of negative indicators (like emissions).

The assessment consists of the steps defining indicators, calculation of ratio Shell/BP and normalization, environmental assessment (including rules), social assessment (including rules), economic assessment and integrated assessment. Because there is more than one indicator for the environmental and social dimension, they have to be combined to an environmental and a social assessment. The results are expressed as linguistic variables environmental assessment and social assessment with the terms "better", "identical" and "worse" on a scale from 0 to 100 points with triangulare membership functions.

Table 2: $\quad$ Indicators and weights [7].

\begin{tabular}{|c|c|c|c|c|}
\hline Indicator & Weight & Unit & Shell Group & BP Group \\
\hline \multicolumn{5}{|c|}{ Economic } \\
\hline $\begin{array}{l}\text { Cash flow after taxation relative to } \\
\text { unit of production (UP, mass of oil } \\
\text { equivalents) }\end{array}$ & 0.120 & $\mathrm{USD} / \mathrm{t}$ & 64 & 58 \\
\hline $\begin{array}{l}\text { Fraction of } \mathrm{R} \& \mathrm{D} \text { expenditure in } \\
\text { gross profit }\end{array}$ & 0.281 & $\%$ & 1.7 & 1.2 \\
\hline Exploration cost relative to UP & 0.363 & $\mathrm{USD} / \mathrm{t}$ & 7.59 & 3.02 \\
\hline $\begin{array}{l}\text { Environmental and safety fines and } \\
\text { penalties cost }\end{array}$ & 0.236 & MUSD & 17 & 7 \\
\hline \multicolumn{5}{|c|}{ Environmental } \\
\hline Mass ratio of $\mathrm{CO}_{2}$ emissions to UP & 0.061 & $\mathrm{~kg} / \mathrm{t}$ & 545.12 & 437.17 \\
\hline Mass ratio of $\mathrm{CH}_{4}$ emissions to UP & 0.055 & $\mathrm{~kg} / \mathrm{t}$ & 1.20 & 1.34 \\
\hline Mass ratio of $\mathrm{SO}_{2}$ emissions to UP & 0.110 & $\mathrm{~kg} / \mathrm{t}$ & 1.50 & 0.84 \\
\hline Mass ratio of $\mathrm{NO}_{\mathrm{x}}$ emissions to UP & 0.103 & $\mathrm{~kg} / \mathrm{t}$ & 1.13 & 1.23 \\
\hline $\begin{array}{l}\text { Mass ratio of hazardous waste to } \\
\text { UP }\end{array}$ & 0.263 & $\mathrm{~kg} / \mathrm{t}$ & 2.85 & 1.33 \\
\hline Mass ratio of spills to UP & 0.407 & $\mathrm{~kg} / \mathrm{t}$ & 0.03 & 0.02 \\
\hline \multicolumn{5}{|c|}{ Societal } \\
\hline $\begin{array}{l}\text { Fraction of societal and community } \\
\text { investment in gross profit }\end{array}$ & 0.0692 & $\%$ & 0.30 & 0.25 \\
\hline $\begin{array}{l}\text { Number fraction of fatalities per } \\
\text { employee }\end{array}$ & 0.2744 & $\%$ & 4.20 & 4.82 \\
\hline $\begin{array}{l}\text { Fatality accident rate for employees } \\
\text { and contractors }\end{array}$ & 0.2410 & $1 / \mathrm{Mh}$ & 5.40 & 3.80 \\
\hline $\begin{array}{l}\text { Recordable injury frequency for } \\
\text { employees and contractors }\end{array}$ & 0.4154 & $1 / \mathrm{Mh}$ & 2.30 & 3.05 \\
\hline
\end{tabular}

Table 3: $\quad$ Composite sustainable development index and sub-indices [7].

\begin{tabular}{|l|c|c|c|}
\hline Index & Weights & Shell Group & BP Group \\
\hline Economic Sub-index I $\mathrm{ECN}$ & 0.329 & 0.467 & 0.607 \\
\hline Environmental Sub-index I $\mathrm{ENV}_{\mathrm{SOC}}$ & 0.407 & 0.470 & 0.904 \\
\hline Societal Sub-index I & 0.264 & 0.784 & 0.700 \\
\hline \hline
\end{tabular}




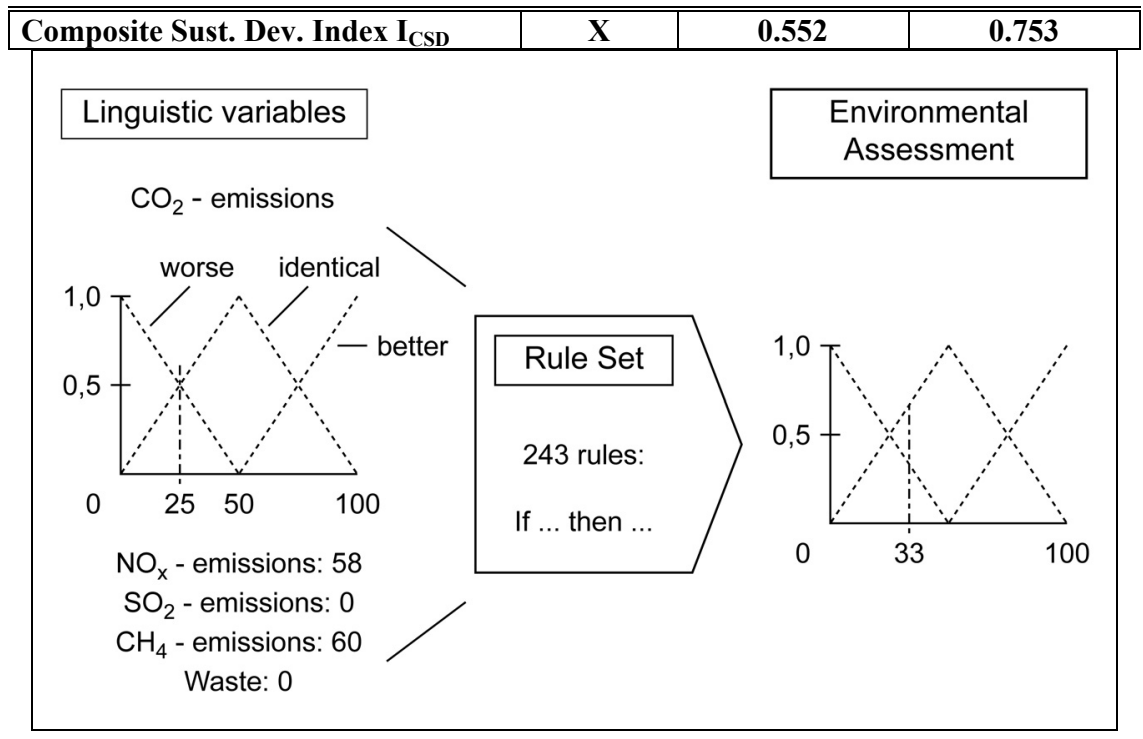

Figure 1: Environmental assessment.

For the environmental assessment the indicators are transformed to linguistic variables. Figure 1 shows this for the criterion $\mathrm{CO}_{2}$ emissions: The normalized input value is 25 (ratio BP to Shell is 1.25); this means that the terms "worse" and "better" are relevant. All linguistic variables are combined with 243 rules ( 5 variables with 3 terms); these rules define the assessment and reflect the preferences of the assessor.

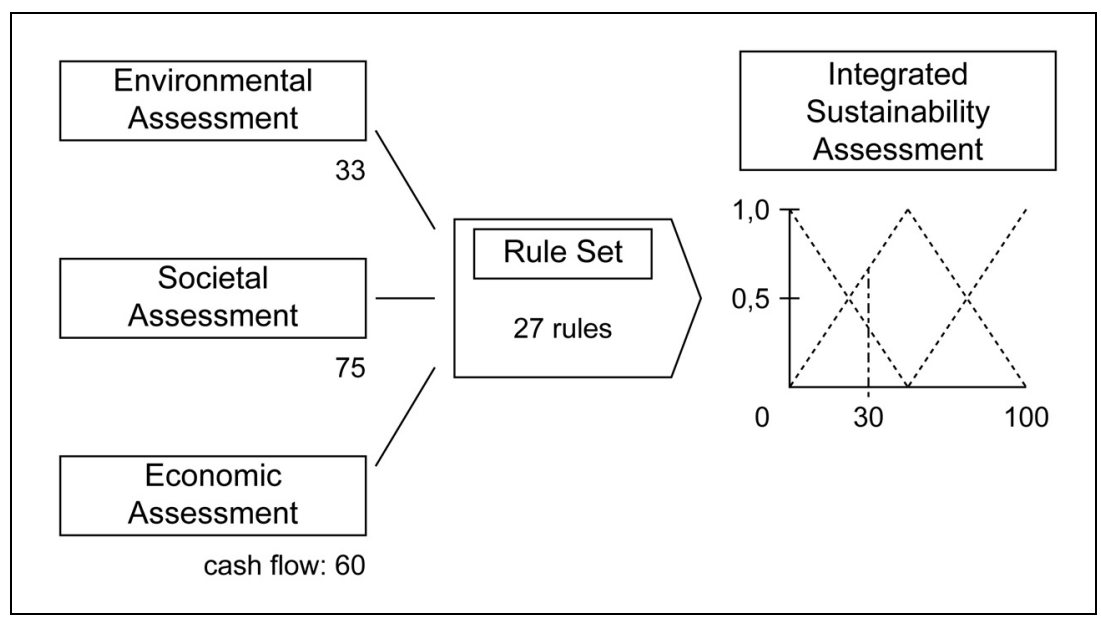

Figure 2: General assessment.

An example for a rule is: If $\mathrm{CO}_{2}$-emissions are "worse" and $\mathrm{NO}_{x}$-emissions are "better" and $\mathrm{SO}_{2}$-emissions are "worse" and $\mathrm{CH}_{4}$-emissions are "identical" 
and waste is "better", than environmental assessment is "identical". The assessment results in a defuzzified value of 33 (see Figure 1). The indicators of the social dimension fraction of societal and community investment in gross profit with an normalized value of 64 and recordable injury frequency for employees and contractors with an normalized value of 75 are combined with 9 rules to the social assessment. The defuzzified value for the social assessment is 75.

For the general assessment, the social, environmental and economic assessments are combined with 27 rules. The economic dimension is measured with the indicator cash flow; the normalized value of cash flow is 60 . The assessment results after defuzzification in 30 points on a scale from 0 to 100 points (see Figure 2). This means that Shell is performing worse compared to BP Group. The performance of Shell in the economic and social dimension is better, but in the environmental dimension worse where Shell has higher emissions of $\mathrm{CO}_{2}, \mathrm{SO}_{2}$ and waste.

\section{Conclusion}

In this paper methods for the assessment of corporate sustainability assessment are described and compared. All presented methods are practicable in the sense that they are able to assess corporate contributions to Sustainable development. The methods are either based on monetary or on non-monetary units. Sustainable value can assess relative contributions to sustainable development; the other methods can assess also absolute contributions to Sustainable development if absolute sustainability goals are used as benchmark. The results of the example Shell and BP shows that all methods assess the performance of BP group better than the performance of Royal Dutch/Shell.

\section{References}

[1] World Commission on Environment and Development. Our Common Future. Oxford: Oxford University Press; 1987

[2] Robért, K.-H., Schmidt-Bleck, B., Aloisi de Laderel, J., et al. Strategic sustainable development - selection, design and synergies of applied tools. Journal of Cleaner Production. 2002; 10(3): 197-214

[3] Figge, F., Hahn, T. Sustainable Value Added - Measuring corporate contributions to sustainability beyond eco-efficiency. Ecological Economics. 2004; 48(2): 173-187

[4] ADVANCE. Sustainable Value of European Industry: A value-based analysis of the environmental performance of European Manufacturing Companies (full Version): The advance project (www.advanceproject.org); 2006.

[5] Figge, F., Hahn, T. Sustainable Value in the Minerals Industry. In: Martens, P. N., ed. Sustainable Development Indicators in the Minerals Industry. Vol 1. Aachen International Mining Symposia ed. Essen: Glückauf; 2005: 
[6] Krajnc, D., Glavic, P. A model for integrated assessment of sustainable development. Resources, Conservation and Recycling. 2005; 43: 189-208

[7] Krajnc, D., Glavic, P. How to compare companies on relevant dimensions of sustainability. Ecological Economics. 2005; 55(4): 551 - 563

[8] Saaty, T. L. Analytical Hierarchy Process: Planning, Priority Setting, resource Allocation. New York: McGraw-Hill; 1980

[9] Baumgartner, R. J. Sustainability Assessment - Einsatz der Fuzzy Logic zur intergrierten ökologischen und ökonomischen Bewertung von Dienstleistungen, Produkten und Technologien. In: Bauer, U., Biedermann, H., Wohinz, J. W., eds. Techno-ökonomische Forschung und Praxis. Wiesbaden: DUV; 2004

[10] Baumgartner, R. J. Dealing with uncertainty: Integrated Sustainability Assessment based on Fuzzy Logic. In: Kungolos, A. G., Brebbia, C., Beriatos, E., eds. Sustainable Development and Planning II (Volume 1). Southampton/Boston: Wit press; 2005:

[11] Zadeh, L. A. Fuzzy Sets. Information and Control. 1965; (8): 338-353

[12] Mechler, B., Mayer, A., Schlindwein, A., Wolke, R. Fuzzy Logic: Einführung und Leitfaden zur praktischen Anwendung. Vol 1. Bonn; Paris; Reading, Massachusetts: Addison-Wesley; 1993

[13] Bojadziev, G., Bojadziev, M. Fuzzy Logic for Business, Finance, and Management. In: Zadeh, L. A., Hirota, K., Klir, G., Sanchez, E., Wang, P.-Z., Yager, R., eds. Advances in Fuzzy Systems - Applications and Theory. Singapore, London, New Jersey: World Scientific; 1997

[14] Figge, F. Öko-Rating: ökologieorientierte Bewertung von Unternehmen. Berlin: Springer; 2000

[15] www.advance-project.org (09.05.2006) 